\title{
Aurelio Pérez Peña y los inicios de la literatura sonorense
}

\author{
Robert McKee Irwin*
}

Resumen:

Este artículo rescata la historia perdida de un gran pionero del periodismo independiente y de la literatura sonorenses. La obra literaria más importante del editor de $\mathrm{E} l$ Imparcial (G uaymas 18891910), es la obra de teatro H eróna. Publicada en 1897, resulta ser el primer libro de contenido literario publicado en Sonora. $\mathrm{He}$ roína trata la invasión de Guaymas por el conde Gaston de Raousset Boulbon y su tropa de filibusteros franceses en 1854. Pérez Peña se empeña en una lucha de representación no tanto con los franceses sino con la prensa norteamericana - cuya visión romántica del conde le pareció equivocada- y también con la historiografía nacional, la que borró una serie de personajes de la historia local, entre ellos dos heroínas de la batalla de Guaymas: Loreta Encinas de Avilés y G uadalupe Cubillas.

Palabras clave:

Aurelio Pérez Peña, H eroína: drama histório nacional, literatura mexicana, literatura sonorense, siglo XIX, G astón de Raousset Boulbon.

Según Gilda Rocha la literatura sonorense nace sólo con la caída del porfiriato en la década de los 1910, ${ }^{1}$ y aunque se ha empezado

* Profesor-investigador. University of California, D avis.

${ }^{1}$ La primera novela sonorense, según Rocha, es D ías del amor de César del Vando de 1911. 
a rescatar el cuerpo de literatura, sobre todo poesía, publicado en periódicos sonorenses desde 1856 (Aldaco Encinas), ningún estudio de la literatura regional menciona la publicación de libros literarios en Sonora en el siglo XIX. No obstante, enterrado profundamente en los almacenes empolvados de libros poco (o a veces jamás) consultados de la Biblioteca Bancroft de la Universidad de California en Berkeley, tuve la fortuna de descubrir un libro publicado en 1897 en Guaymas que parece ser el primer tomo literario publicado en el estado. Se trata de una obra de teatro escrita por un periodista bien conocido en Guaymas y Hermosillo en las últimas décadas del porfiriato. El autor se llama Aurelio Pérez Peña y la obra se titula H eroína: drama histório nacional.

Olvidado por décadas, quizás por el hecho de que no existiera la literatura fronteriza en ese entonces - como no había tradición literaria, no había dónde guardarlo en la memoria pública de la región- este pequeño libro establece los inicios de la producción literaria sonorense como manifestación de un diálogo con tanto la cultura nacional mexicana como la estadounidense. La identidad regional se empieza a construir como producto de este diálogo por la necesidad de los sonorenses de distinguirse de y también vincularse con aspectos estratégicos de estas dos culturas nacionales. Como veremos, la cultura sonorense del fin de siglo XIX es ardientemente mexicana; los sonorenses son defensores de la integridad nacional ante la amenaza imperialista del norte. Pero la naciente identidad regional asume también otros rasgos conforme a ciertas creencias yanquis. Esta identidad sonorense es una invención que no toma en cuenta la diversidad étnica del estado, pero que insiste en marcarse finalmente como mexicana y no yanqui, y que se impone respaldada por la historia "verdadera", la cual corrige la historia oficial. Aurelio Pérez Peña es periodista, es literato, es historiador, es forjador de la cultural regional sonorense. Vale la pena resucitar su nombre junto con los de las olvidadas heroínas (y también los héroes) de Guaymas de 1854, las que protagonizan (o un caso, el que no protagoniza) la obra polémica de Pérez Peña. 


\section{Aurelio Pérez Peña y El Imparcial}

El Imparcial fue publicado principalmente en Guaymas - y eventualmente en Hermosillo, según los inconvenientes políticos del equipo editorial del momento - de 1889 a 1910, haciéndole uno de los periódicos independientes de mayor duración y también de mayor circulación del Sonora prerrevolucionario (Moncada 0. 8, 26, 223, 226). Pérez Peña inició su trayectoria profesional como periodista, pero en 1892 asumió el control editorial de El Imparcial cuando su editor fundador, Ernesto Peláez se retiró. Aparte de sus responsabilidades como jefe de redacción y reportero principal, Pérez Peña contribuyó con frecuencia a las páginas de su periódico textos literarios, contando entre sus escritos tanto cuentos como poesías. Sus lectores sonorenses de los 1890 lo conocían principalmente por su seudónimo "Eliseo". Siguió en este cargo hasta que el periódico dejó de publicarse con el estallido de la revolución mexicana.

Del contenido de El Imparcial se puede vislumbrar la concepción particular de identidad y cultura regionales que aspiraba construir y promover Pérez Peña en los años 1890. ${ }^{2}$ Es una visión que toma en cuenta los lazos culturales que mantenían los sonorenses con ciertos pueblos "cultos" (los franceses y los estadounidenses), y los que no querían tener los sonorenses con las nacionalidades más "bárbaras" (los chinos). El papel de cada cultura extranjera dependía de su utilidad en el proyecto de desarrollo económico y modernización para la oligarquía cultural sonorense que representa Pérez Peña. Tal proyecto defendía la autonomía nacional sin necesariamente conformarse con todos los rasgos de la cultura mexica-

${ }^{2} \mathrm{He}$ podido estudiar en detalle los números de $\mathrm{E} I$ Imparcial publicados desde el mes de septiembre de 1892 hasta el de junio de 1895, los que forman parte de las colecciones conservadas en el Fondo Reservado de la Hemeroteca Nacional en la ciudad de México. No sé si estos años son representativos de la obra periodística de Pérez Peña, pero sí presentan su trayectoria en el momento en el que se concibió la elaboración de H eróna. Parece que no hay otro archivo que conserve más que ocasionales ejemplares sueltos de este periódico. 
na establecidos por otra oligarquía cultural a nivel nacional. Forjó Pérez Peña una cultura distintamente regional, pero a su gusto. Incorporó ciertos elementos no necesariamente enfatizados en construcciones de lo mexicano mientras que elidía otros menos convenientes, sobre todo los que reflejaban aspectos incómodos de relaciones entre sonorenses de diferentes razas o clases sociales. Fomentó tanto por el periodismo como por la literatura una visión de la cultura regional que antes nunca se había articulado bien por falta de medios de producción cultural. El periodismo independiente y literatura regional de Pérez Peña y de otros letrados pioneros culturales de la época en Sonora echaron los cimientos de la cultura fronteriza que se ha ido definiendo con mejor nitidez durante el último siglo.

El enfoque del presente trabajo, sin embargo, no es la trayectoria periodística de Pérez Peña, ${ }^{3}$ sino su seminal intervención literaria. Su tema fue la defensa de Guaymas ante su invasión por filibusteros franceses en 1854. Pérez Peña dialoga con la historiografía y fomenta su construcción particular de la identidad regional al publicar H eroína en 1897.

\section{Los héroes de Guaymas: el contexto histórico}

D espués de la guerra de 1846-48 con Estados Unidos, empezaron a llegar al noroeste mexicano un desfile de invasores filibusteros, aventureros gringos y a veces franceses que salían de San Francisco y San Diego con ilusiones de conquista y gloria. ${ }^{4}$ Sonora y Baja California se eligieron con frecuencia como blanco por dos razones: primero, la creencia que esta zona tenía muchísimas riquezas minerales todavía no explotadas, y segundo, el problema persistente de los indígenas (los yaquis, los apaches, los seris) que había dificultado la colonización del territorio - es decir que era tierra virgen todavía, la que a lo mejor ocultaba tesoros inmensos. Sonora

\footnotetext{
${ }^{3}$ Para un análisis detallado del periodismo de Pérez Peña, ver Irwin.

${ }^{4}$ Sobre los filibusteros en Sonora, ver Ruibal Corella 135-50.
} 
y Baja California, zonas ricas y despobladas, podrían fácilmente conquistarse y/ o independizarse y luego anexarse a otro país más fuerte.

Uno de los invasores más notables de estos años fue el conde francés llamado Gastón de Raousset Boulbon. Raousset vino a México por primera vez de San Francisco - adonde había ido en busca de fortuna fácil (pero llegando demasiado tarde) en la época de la rebatiña de oro- en 1852, bajo el patrocinio de un banco franco mexicano, con el propósito declarado de establecer una colonia minera y agrícola en el norte de Sonora. Los sonorenses, incomodados por la apariencia militar de los colonos franceses que le acompañaron, no lo recibieron bien. Las negociaciones con respecto a sus derechos y responsabilidades en el estado no avanzaban y Raousset perdió la paciencia, invadiendo la ciudad de Hermosillo, la que los franceses prontamente "liberaron", aunque su ocupación de la ciudad fue muy breve. Poco después los franceses fueron vencidos por los mexicanos y, gravemente enfermo de disentería, Raousset retiró su tropa y la mandó de regreso a California.

Sin embargo, no se desalentó el conde. Cuando volvió a San Francisco, le recibieron como héroe, inspirando en él el deseo de reanimar su proyecto filibusterista. Fue primero a la ciudad de México para negociar algún tipo de pacto de colonización con el presidente Antonio López de Santa Anna, pero este intento falló y el francés volvió frustrado a San Francisco. Allí empezó a reclutar a un cuerpo de hombres para invadir Sonora y ganarle su independencia, lo cual según aseveraba él, les ganaría el respaldo de los sonorenses, quienes, aseguraba, estaban unánimemente frustrados por el descuido que padecían bajo el gobierno corrupto de Santa Anna.

Mientras tanto, los mexicanos, informados de sus intenciones, reclutaron su propia milicia de mercenarios (principalmente franceses) para vigilar los intereses mexicanos en la frontera. No obstante, una vez formada esta milicia, Raousset se presentó en Guaymas y asumió el control de la tropa. El general mexicano José María Yáñez intentó negociar una resolución pacífica al desacuerdo entre los mexicanos y el conde, el que quería privilegios para que su compañía armada colonizara libremente en el estado. Antes de que se 
avanzaran mucho las discusiones, Raousset decidió atacar el puerto de G uaymas. La batalla histórica aconteció el 13 de julio de 1854 . D entro de sólo unas horas, se había acabado. Los mexicanos, quienes contaban con menos hombres que los franceses, fueron respaldados por la gente patriótica de Guaymas y también por unos chilenos, irlandeses y alemanes que habían desertado al ejército filibustero. Los mexicanos entonces vencieron decisivamente a los franceses y unos meses después fusilaron a Raousset. ${ }^{5}$

\section{La historia oficial: los hombres ilustres}

Los primeros en publicar extensivamente sobre las aventuras de Raousset eran los franceses. ${ }^{6}$ Una cantidad de libros, entre ellos algunos escritos por participantes en la batalla de $\mathrm{G}$ uaymas y otros compilados basados en la correspondencia personal del conde, aparecieron en París en la década que seguía su muerte. Mientras que el gobierno francés se había distanciado oficialmente de las proezas de Raousset, sus aventuras proveían por lo menos unas lecciones para Napoleón III, quien invadiría y ocuparía el país unos doce años después. Los franceses se apuraron para publicar una novela escrita por el conde cuya introducción muestra lo que sus aventuras significaban en Francia. En lugar de enfocarse en su derrota militar en Guaymas, los editores de U ne onversion preferieron elogiar al difunto autor como "le vainqueur d'Hermosillo".

Mientras que los testimonios franceses proveerían la base principal de las primeras historias de las expediciones de Raousset en México, los informes oficiales del general Yáñez de su victoria circulaban principalmente en los periódicos de la ciudad de México y de la frontera noroeste, ofreciendo a sus lectores la perspectiva de su

${ }^{5}$ La bibliografía sobre este acontecimiento histórico es extensa; el texto originario es el informe de José María Yáñez; algunos de los textos más importantes sobre el tema incluyen: Wyllys, Ramírez Cabañas, Sobarzo, Truebay López Encinas.

${ }^{6}$ Margo G lantz hizo una recopilación de algunos de sus textos más importantes.

${ }^{7}$ Estaintroducción no tiene paginación. 
lado. El enfoque mexicano en el liderazgo de Yáñez y el patriotismo de la tropa mexicana y los voluntarios locales ante el imperialismo extranjero, se contrastaba bastante con el interés francés en lo intrépido de los aventureros franceses en un rincón exótico del Nuevo Mundo. Pero ¿eran estas dos versiones suficientes para representar bien los acontecimientos del 13 de julio de 1854?

\section{Una interpretación yanqui}

En el año 1853, por aproximadamente once meses, la revista popular neoyorquina, The $\mathrm{N}$ ational Police $\mathrm{G}$ azette, con amplia circulación nacional entre hombres aficionados de los deportes (particularmente el boxeo), los crímenes escandalosos, las aventuras sensacionales y las bellas estrellas del teatro, lanzó una iniciativa innovadora. Publicó una versión del mismo periódico en español que se distribuyó por todo el mundo hispano, desde las ciudades con significativas poblaciones hispanoparlantes de los Estados Unidos a las grandes capitaleds de América Latina, con su mayor distribución internacional en Cuba y México. ${ }^{8}$

El primer número de $\mathrm{L}$ a $\mathrm{G}$ aoeta de Policáa, de una forma u otra, llegó a manos de Aurelio Pérez Peña, evocando en él una ira que con los años les llegaría a ser familiar a sus lectores, esta cólera provocada por la representación injusta de la cultura mexicana en la prensa estadounidense. En este caso las "pornográficas históricas" de L a G acta de Polića le afectaron casi personalmente ya que trataron la historia no sólo de México sino ahora de G uaymas. Tuvieron los yanquis las agallas de contar una versión de la invasión de Guaymas del conde de Raousset Boulbon, la cual le hizo héroe al filibustero francés y que malrepresentó a los mexicanos como unos bárbaros. Vale la pena citar el artículo en extenso:

${ }^{8}$ D esafortunadamente, parece que estos números de $\mathrm{T}$ he $\mathrm{N}$ ational Police $\mathrm{G}$ azette ( $L$ a $G$ acta de Policía) no se han archivado en ningún lugar. Se sabe de ellos sólo por los anuncios que aparecieron desde finales de 1892 hasta finales de 1893 en la versión anglófona del periódico. 
Hilaridad nos ha causado ver en un periódico que se publica en Nueva York... trazadas las hazañas galantes y caballerescas del Príncipe de Sonora Conde Rousset de Boulbon [sic]. Ojos más acostumbrados a lágrimas que los nuestros llorarían al leer la relación de las peregrinas desgraciadas ocurridas en Sonora al más santo, virtuoso y amable caballero que la leyenda ha conocido. (6/ 2/ 1893: 2, énfasis en el original)

El artículo no fue firmado por Eliseo, pero su tono se parece muchísimo al de otro artículo firmado por éste sobre el tratamiento del tema de las insurrecciones fronterizas de Catarino Garza en la prensa gringa, publicado menos de un mes antes, en donde se refiere a "los buenos mexicanos que hay en la frontera, los que verdaderamente son mexicanos" y que "aman a su patria" - a diferencia del malagradecido Garza, demasiado admirado por los gringos (12/ 1/ 1893: 1). Sobre el caso de L a G aota de Policáa, sigue el autor anónimo:

La leyenda famosa la tomaríamos como una broma risible de un payaso de faz embadurnada de albayalde en función de feria de pueblo, si el caso fuera aislado; pero otros periódicos norteamericanos han publicado sobre el mismo asunto sandeces de tan desusuada medida, calumnias tan despreciables, que es de sentirse no se pueda escribir un hasta aquí con la punta de un zapato mojado en un estercolero en vez de con una pluma honrada. (6/ 2/ 1893: 2, énfasis en el orginal)

Se ofendió el autor no sólo por el contenido de esta historia sino también por el material en general que le acompañaba en la revista neoyorquina:

La leyenda es anónima (como es de suponerse) pero contiene tales majaderías, como sólo se ven estampadas en periódicos de pornografía escandalosa destinados a circular en manos de viejos libidinosos, jóvenes corrompidos o mesalinas impúdicas. (6/ 2/ 1893: 2, énfasis en el original) 
El tema no volvió a tocarse en los días posteriores. Poco más de un mes después de la publicación del artículo, Pérez Peña, quien había sido director de redacción, volvió propietario del periódico con el retiro de su fundador Ernesto Peláez el 8 de marzo. Aparentemente sus responsabilidades como director y redactor de $\mathrm{E} I \mathrm{Im}$ parcial le ocuparon totalmente el tiempo durante los próximos años -y no le simplificaron la vida sus disputas con ciertos políticos, las que culminaron en su encarcelamiento durante varios meses en 1893 y 1894 (Moncada 0. 44-48). Así que sólo en 1897 se inspiró a publicar su respuesta definitiva a L a $\mathrm{G}$ aceta de Polića, la que también resultó ser una respuesta a José María Yáñez y la versión nacional (centrista) de la historia sonorense.

\section{Henoína}

H eroína, según su portada, es una obra "en tres actos, en prosa y verso" para catorce personajes más muchedumbre ("urbanos de Guaymas, soldados mexicanos y franceses, pueblo, etc., etc." 4). Aunque su contenido político resulta mucho más interesante que su forma literaria, vale la pena notar unos aspectos de su composición.

$\mathrm{El}$ primer acto consiste en seis escenas en las que se presenta el contexto inmediato de la invasión de Guaymas de 1854. La acción es nula: todo se expone por medio del diálogo, primero entre el vicecónsul de Francia y el coronel D esmarais, jefe oficial de la tropa francesa, y luego entre Desmarais y el conde de Raousset Boulbon. D esmarais tiene también un monólogo (la Escena II) donde expresa su debilidad ante el carisma del conde.

El drama es débil. Para el público que conoce bien su historia, todo es obvio. Raousset va a asumir el control de los franceses y atacar el puerto de G uaymas desde adentro. Para el público no bien informado, no hay suficiente contexto para entender la gravedad de las circunstancias. La incursión anterior de Raousset en Sonora no se menciona, ni tampoco se explica bien la presencia de la tropa francesa en $\mathrm{G}$ uaymas. Entonces, en la cuarta escena, cuando entra al foro por primera vez Raousset y anuncia sus intenciones, el im- 
pacto emocional no está muy elevado, aun después de un breve discurso del conde que termina con un grito de entre bastidores de "iiViva el conde Raousset!!" (11).

Dialogan entonces los franceses con el general Yáñez. En la Escena V, la arrogancia del conde ante el patriotismo humilde pero resuelto de Yáñez produce el contraste inevitable entre quienes aparentemente van a ser los grandes protagonistas de la obra. El Acto Primero termina entonces con el filibustero, ya claramente habiendo usurpado el papel de D esmarais, animando a la tropa, "lo que mi astucia y diplomacia no han podido conseguir, lo conseguirán la fuerza y arrojo de nuestras armas" (16), a lo que responden los soldados franceses, "iA las armas! ja las armas!" (16).

En el segundo acto, la escena ya es el cuartel mexicano. Allí Yáñez, todavía no enterado de la inminencia del peligro, sigue dialogando con el vicecónsul francés. Pronto entra el coronel Campuzano para informarle a Yáñez de una riña entre soldados franceses y mexicanos en una cantina. Siguen hablando tras varias escenas de los posibles peligros. En la Escena VII, el general Yáñez tiene su monólogo se angustia del peligro, reprocha a los franceses por su codicia y mendacidad, y finalmente elogia las bellezas de la patria:

¡Ah Sonora! ¡Ah, patria mía! Tus riquezas, tus dones infinitos; tus mujeres, bellas como las huríes prometidas de Mahoma; tus campos cuajados del oro de la espiga; tu mar azul que besa sumiso tus rosadas plantas; tu tierra cuyas entrañas lleva secretos y vírgenes tesoros... Todos los dones maravillosos con que te ha regalado la naturaleza, son causa de la desgracia que amenazadora y sombría se cierne sobre tu cabeza... (23)

En la siguiente escena, Yáñez recibe información de un espía alemán acerca de los preparativos de los franceses. Luego, en las próximas escenas, llegan ciudadanos varios de Guaymas al cuartel para ofrecerse como voluntarios en la inminente batalla: Jorge Martinón y los estudiantes de la escuela, otros treinta y pico mu- 
chachos del pueblo, y hasta un par de niños llevados por su mamá ante el general mexicano. Durante las primeras once escenas, la emoción va intensificándose hasta que en la Escena XII del Acto Segundo, entra doña Loreta de Avilés corriendo y gritando, " $\mathrm{Ya}$ vienen señor! iya vienen!... ¡Ya salieron del cuartel! ¡Los he visto, señor!" (28). Con la llegada de este personaje, quizás se inicia el drama verdadero de la obra. El nombre de la señora de Avilés y no el de Raousset o de Yáñez es de los primeros en la lista de personajes, precedido sólo por el de Guadalupe Cubillas. ¿Quiénes son estas mujeres? ¿Por qué sus nombres se resaltan más que los de los jefes militares? ¿Por qué, en fin, se llama esta obra H eroína?

\section{La literatura: mejor medio para contar la verdad}

H eroína, se elaboró para corregir la perspectiva extranjera que glorificaba a los franceses a expensas de los mexicanos, y también para rectificar el informe de Yáñez, el que parece haberle fastidiado a su autor por incompleto. Al haberse topado con "copiosos datos documentados relativos a los gloriosos sucesos de julio de 1854" ( $\mathrm{He}$ roína 3: "El por qué de este drama"), Pérez Peña preparó esta obra de teatro para que se representara ante un público inequívocamente local. En su introducción de autor, Pérez Peña hace hincapié en el placer que le dio al escuchar los aplausos de las mujeres y los niños de $\mathrm{G}$ uaymas de sus primeras representaciones en el foro (3). $\mathrm{H}$ eroína no se trata principalmente de Raousset y los filibusteros franceses, pero tampoco se ocupa demasiado con el general Yáñez y las fuerzas armadas mexicanas, aunque estos dos grandes hombres sí jugaron papeles importantes en el drama. H eroína contesta radicalmente a todas versiones previas, las cuales había reconstruido la batalla de Guaymas, en la gran tradición de la his-toriografía, como encuentro violento entre dos naciones protagonizado por dos hombres ilustres y sus seguidores anónimos. $\mathrm{H}$ eroína asume una perspectiva regional al acentuar la importancia de algunos protagonistas guaymenses, los que hasta ese entonces se habían excluido de la historiografía oficial. Estas figuras marginalizadas abarcaron 
voluntarios civiles, mujeres, niños, ancianos y hasta residentes extranjeros de Guaymas. Algunos ni siquiera se mencionaron en los informes de Yáñez, pero sí siguieron vivos en el imaginario público como protagonistas de la tradición oral.

Entre estas figuras legendarias (es decir que no oficialmente históricas) contaron doña Guadalupe Cubillas y doña Loreto Encinas de Avilés, las que como mujeres no tenían lugar propio en la relación de la lucha nacional. Su reinserción en la historia por Pérez Peña como heroínas le permite al autor reconfigurar el significado histórico a fin de que ya no sea estrictamente nacional, sino más local e inevitablemente fronterizo. También es interesante advertir que había otra figura cuya putativa participación en la batalla de Guaymas era bien conocida para los sonorenses, aunque también se omitía de la historiografía oficial nacional; empero este personaje no fue incorporado en la nueva historia de Pérez Peña. Este personaje en el año de 1854 era el jovencito José María Leyva, mejor conocido para el fin de siglo como el temible líder de las rebeliones yaquis de los años 1870 y 1880, Cajeme. En fin, lo que hizo Pérez Peña fue construir, por un proceso de inclusiones y exclusiones selectivas de protagonistas, una historia de la frontera noroeste mexicana, la que es tanto una contribución importante a la integridad nacional como una representación digna del contexto fronterizo en el que se llevó a cabo.

En la lista de protagonistas de H eroína, los nombres de los personajes aparecen en el siguiente orden: $\mathrm{G}$ uadalupe Cubillas, Loreto de Avilés, "una mujer del pueblo", el general Yáñez, el vicecónsul francés, el coronel Campuzano, el conde Raousset, etc. El orden es importante porque a diferencia de las versiones francesas y gringas, el conde francés es empequeñecido por el general mexicano -y uno de los subordinados, Campuzano, quien no es del D. F. como Yáñez sino de Guaymas- y hasta por el vicecónsul francés. Pero lo más asombroso es el hecho que los primeros tres personajes en la lista sean mujeres; y ninguna de estas mujeres había recibido reconocimiento significativo en la historiografía oficial. Cubillas y Avilés son las heroínas de G uaymas cuyos nombres Pérez Peña inmortaliza en su obra. 


\section{La heroína Loreto de Avilés}

Loreto es la heroína cuyo aviso llega justo a tiempo para evitar un desastre - a pesar del hecho que cuando llega, parece que está todo el pueblo en las calles, armado y aprestado para el ataque de los franceses, todos gritando “¡Viva Sonora! ¡Viva México! ¡Muera Raousset! ¡Viva el general Yáñez!” (28). En la Escena XIII del Acto Segundo, Loreto es la estrella: su monólogo, una oración patriótica. D e hecho, es ella la protagonista principal de la segunda mitad del segundo acto; el público experimenta los pormenores de la batalla con ella. En sus tres últimas escenas cortas, doña Loreto recibe información sobre la batalla del viejo Moreno, un anciano que presencia los pormenores de la batalla por una ventana; cura a los heridos que llegan; escucha la noticia de la toma de la casa Díaz, la que les dispersó a los franceses que la había ocupado a la calle; y se entera luego de la liberación del último baluarte de la breve ocupación francesa, el Hotel Sonora. Así termina la batalla - entre bastidores: Moreno grita, "iiiV ictoria!!!” y luego se cae de rodillas junto con Loreto mientras los dos exclaman, "iiG racias, Dios mío, gracias!!" Con esto la orquesta prorrumpe en una rendición esplendorosa del himno nacional y baja el telón.

El papel de doña Loreto es algo ambiguo. Parece que llegó casi tarde, cuando todos ya estaban listos para el asalto inevitable, ésta enterándoles a todos de lo que ya sabían. No obstante, Pérez Peña le hace destacar tanto a esta señora que ésta ya exige reconocimiento como heroína. Además, como el público se informa con ella de lo que está sucediendo de entre bastidores en la batalla, y por eso se identifica con ella, Loreto finalmente representa el pueblo de Guaymas, la sociedad civil.

Al mismo tiempo, fue un personaje verdadero cuyo papel en los eventos de 1854 se había discutido ya por más de una década en G uaymas. ${ }^{9}$ Matriarca de una distinguida familia guaymense que si-

${ }^{9}$ Es probable que la fuente de Pérez Peña sobre Loreto de Avilés sea un discurso presentado por el abogado Arturo Jáuregui, originario de la ciudad de México, en 1886 (citado en López Encinas 76). 
guió desempeñando un papel importante en la celebración del 13 de julio por décadas, ${ }^{10}$ representó doña Loreto el patriotismo del pueblo guaymense a todos niveles ante el asalto extranjero y fue ella la más visible de los muchos participantes no militares en la batalla de Guaymas. Mostró que la batalla fue más que una confrontación militar; fue un triunfo de la cooperación comunitaria. La ciudad cosmopolita de Guaymas quizás estaba ya acostumbrada a los residentes y visitantes extranjeros, ${ }^{11}$ pero no estaba dispuesta a que los forasteros vinieran a apoderarse de su soberanía.

\section{La heroína Guadalupe Cubillas}

El tercer acto de $\mathrm{H}$ eroína introduce otro personaje marginalizado por la historiografía oficial, pero de gran importancia simbólica para Pérez Peña. Guadalupe Cubillas era otra leyenda guaymense cuyo nombre había resurgido hacía unos pocos años. En 1894, Francisco Dávila, en su Sonora histórico y descriptivo, libro prologado por su amigo Pérez Peña, rescató otra leyenda de 1854 al relatar el papel importante de Cubillas en la rendición de Raousset. ${ }^{12}$

Dávila sigue muy fielmente la versión de Yáñez, citándola por extenso, pero luego introduce (sin citar fuente alguna) la anécdota de Cubillas, quizás para ridiculizar a Raousset. Dávila fija lo que había sido una figura efímera y equívoca del periodismo en la

${ }^{10}$ Por ejemplo, en 1920, un nieto de Loreto, Jesús Avilés, participó en la inauguración de un obelisco conmemorativo dedicado a los héroes de 1854 (López Encinas, primera página-no paginada). En tiempos más recientes, los descendientes de doña Loreto han ido contando versiones cada vez más dramáticas de su leyenda, un caso reciente es el de su tataranieta O raliaAvilés de Ferreira de los años 1980, transcrito en López Encinas (103).

${ }^{11}$ Iberri cuenta entre los residentes de G uaymas gente de más de veinte nacionalidades a finales del siglo XIX (71-74).

${ }^{12}$ Las primeras referencias a Cubillas se hallan en diversos periódicos de 1854, tanto en México (por ejemplo, El U niversal de la ciudad de México, 31/ 8/ 1854: 2) como en los Estados Unidos (por ejemplo, The Star de Los Ángeles, 12/ 10/ 1854: 11). Los usos de esta figura han sido inconsistentes. En México, la rendición del 
historiografía, clarificando su relación con el vicecónsul como no la de hermana sino de cuñada cuya casa se ubicaba al lado de la del diplomático francés. ${ }^{13}$ Cuando el conde entró a su casa por error, Cubillas le increpó por llevar armas y sombrero en la presencia de una dama. Raousset cumplió con las reglas de la etiqueta apropiada para un hombre de su clase. Así, fue desarmado por "una mexicana" (26), sometiéndose a "las leyes de honor" (26).

En H eroína, Cubillas es el personaje central del tercer y cuarto actos de la obra. Al subir el telón para iniciar el Acto Tercero, doña Guadalupe se halla sola en su casa, lamentando los acontecimientos del día, con una pistola tendida sobre la mesa en caso de que haya necesidad de protegerse. Este acto entero se presenta en verso.

En la primera escena, la señora Cubillas maldice a Raousset: "iTodo fuiste a un tiempo mismo: infame, ingrato y desleal! ¿En dónde está tu hidalguía? ¿D ónde el brillo del blasón? ¿Qué fue, torpe, tu intención hacer de la patria mía?" (33). La posible ambigüedad de Cubillas como pariente política del vicecónsul francés (detalle omitido por entero por Pérez Peña) se transparenta por completo con esta frase. De hecho, cuando de pronto evoca las figuras de Cuauhtémoc y Morelos, parece que la mera esencia de su identidad es su nacionalidad mexicana. Concluye exaltando el valor y el patriotismo de sus paisanos:

Vengan como torrentes desbordados, los enemigos de mi patria, México; que cada mexicano es un soldado listo a morir peleando sus derechos. Vengan como Raousset: de aquí los reto; y si los cielos permanecen mudos, jaquí están nuestros cuerpos por escudos! (35)

conde ante una "señorita mexicana" expuso la cobardía de éste; en California, tierra de filibusteros y anexionistas, y de gente de gran sentimiento antimexicano, Cubillas se identificó como hermana del vicecónsul francés, y la capitulación del conde ante ésta (una francesa) fue un último acto de desafío arrogante hacia los mexicanos.

${ }^{13}$ D ávila lo identifica erróneamente como cónsul. 
En este momento, Cubillas se asusta al reparar en la entrada de nadie más que el nefario conde de Raousset Boulbon a su casa, rogándole (todavía en verso) que le permita ampararse allí: "vienen detrás; escucho sus aullidos; ya me cercan, me alcanzan los bandidos; iprotegedme!" (35). Guadalupe le responde:

pero escuchad, insigne visitante:

sin llamar os entrasteis a esta casa

y aun lleváis el sombrero y vuestras armas.

¿Son tan grandes, señor, vuestras alarmas?

¡Pues sabed que el umbral no los traspasa

de esa puerta que veis, quien no esté cierto

de venir desarmado y descubierto! (36)

El conde queda desconcertado y contesta: " Señora, perdonad! Yo no sabía... ", a lo que replica ella, "¿Q ué ignorabais, señor? Frente a una dama presentarse cual vos, sólo se llama o falta de respeto 0 grosería. ¡Vuestra espada rendid...."' (36).

Cuando Raousset vacila, doña Guadalupe agarra su propia pistola de la mesa y le obliga a cumplir, a lo que reacciona éste, " $\mathrm{iMal}$ dición sobre mí! 'Suerte villana!" (36). Cubillas entonces prorrumpe en una invectiva prolongada (siempre en verso) sobre el daño que Raousset le había hecho al pueblo mexicano, no obstante su linaje noble. Replica él: “ ¡Señora! ¡Me insultáis!” Cubillas le contesta, "Había olvidado que os halláis prisionero y desarmado" (36). El conde queda "sorprendido" y dice, "¿Prisionero decís?" (37). Cubillas nunca se desconfía y lo mantiene siempre bajo su control hasta que llega finalmente el coronel Campuzano (y no el general Yáñez).

Una vez que el conde está entregado a las autoridades militares, la obra va precipitadamente a su fin. D urante una última mutación entre el tercer y el cuarto acto, se le pronuncia (ya no en verso) la sentencia de pena de muerte al conde, y el general Yáñez profiere un homenaje a "Sonora, cuyos hijos, son modelo de honor y patriotismo" (43). Finalmente, en una última escena muda, el conde está conducido hacia el pelotón de fusilamiento: "Al caer el telón, se oye una descarga de fusilería" (43). Como había sido el caso duran- 
te toda la obra, el foro se reserva como espacio para explicaciones y narraciones de parte de actores casi inmóviles mientras la acción dinámica sucede fuera de la vista de la audiencia.

Guadalupe Cubillas, como Avilés, es una heroína de Guaymas, a pesar de haber sido marginalizada de la historia oficial, pero mantenida viva - y maleable- en el imaginario público por medio de la historia oral. Pérez Peña la explota en su apasionadamente inspirada relación de los acontecimientos, y no sólo como otra patriota civil de Guaymas; Cubillas es también una aristócrata, a quien el mismo conde se siente obligado a tratar como una dama. Sonora, entonces, es tierra no de mera gentuza mestiza, sino también de una clase hidalga, adinerada, ilustre y blanca, merecedora del trato educado de un conde francés.

Mientras que las estrategias de Pérez Peña han consternado a unos historiadores que se quejan de que "ya cada personaje femenino que pasa por las amarillentas páginas del libro sonorense, como la señor Avilés o como la distinguida dama D oña Guadalupe Cubillas, se han [sic] convertido en otras tantas heroínas", ${ }^{14}$ la verdad histórica no era su preocupación central. Estaba consciente, en efecto, que la historiografía no cuenta necesariamente la historia completa, y que la historiografía no era siempre el género más eficaz para diseminar la historia. Optó no por su herramienta habitual, el periodismo, para responder a lo que le pareció una acometida extranjera a la historia local, sino por el teatro - donde su obra provocaría un inmediato efecto emocional en su público - y por la literatura - donde su mensaje viviría eternamente. A pesar de que $\mathrm{H}$ eroína no haya logrado el éxito esperado de largo plazo, su intervención sí tuvo un efecto importante en la historiografía. Un libro conmemoratorio de la invasión de Guaymas por Raousset Boulbon de 1907, escrito por Pedro Ulloa, el que contó con una distribución amplia con su segunda edición de 1954, el año del centenario de la

${ }^{14} \mathrm{G}$ arza 378; hay que notar que G arza no indica haber leído H eroína, un texto probablemente ya no disponible en Sonora para mediados del siglo XX, pero sí cita una crítica de Pérez Peña articulada por un informante local (377). 
batalla de G uaymas, sigue cercanamente la versión contada por Pérez Peña en H eroína como si fuera historiografía y no literatura. Para mediados del siglo $\mathrm{XX}$, aunque algunos historiógrafos prominentes (Sobarzo, Trueba) seguían omitiéndolas, gracias a Pérez Peña, Avilés y Cubillas ya habían encontrado su lugar en los textos de historia estatal leídos por miles de niños sonorenses empezando con N ociones de historia del estado de Sonora de Laureano Calvo Berber de 1941.

\section{El héroe doblemente olvidado: Cajeme}

No hay que olvidar que el objetivo de Pérez Peña no era contestar mentiras con verdades sino remoldear la verdad histórica para que ésta incorpore la mejor imagen posible de la cultura fronteriza del noroeste mexicano. Un aspecto de esta cultura que el dramaturgo no quería enfatizar fue la persistente pugna que había entre algunos grupos indígenas menos dóciles que nunca habían sido conquistados en realidad y que seguían defendiendo su autonomía política, geográfica y cultural. Este tipo de conflicto pintaba a la región como no civilizada, peligrosa y poco atractiva para inversionistas yanquis o europeos. Q uizás por eso $\mathrm{H}$ eroína, obra notable por lograr la recuperación de la leyenda local en la historiografía por medio de la intervención literaria, no incluye entre sus protagonistas el nombre de José María Leyva, hombre mejor conocido como Cajeme.

Cajeme, como bien se sabe, era el gran jefe insurgente de los yaquis durante un periodo de intensa resistencia al dominio mexicano de 1875 hasta su captura y fusilamiento en 1887. Cuando José María Leyva, hombre de ascendencia yaqui pero educado en una casa criolla, fue nombrado por las autoridades mexicanas como administrador de la zona de los yaquis, los sorprendió al asumir la causa de los yaquis y declarar su independencia respecto de México, expulsando a todos los extranjeros - incluyendo a los mexicanos no indígenas- de sus territorios. Se conocía por su astucia como líder político y militar, y la rebelión llevada a cabo bajo su mando fue una vergüenza para las autoridades mexicanas. Cuando final- 
mente se aprehendió, el periodista y político Ramón Corral aprovechó para entrevistarlo antes de su fusilamiento. Esta breve biografía, notable por ser la única escrita con la supuesta colaboración del sujeto, se escribió con un tono de admiración y contribuyó significativamente a la construcción de Cajeme como un héroe importante del porfiriato después de la revolución mexicana. ${ }^{15}$

Argumenta el historiador Miguel Tinker Salas que "al representar a Cajeme como figura noble, Corral esperaba cooptar el carácter desafiante de los yaquis" (217). Sin embargo, lo que complica cualquier interpretación de la vida de Cajeme y su representación por Ramón Corral es el hecho de que Cajeme es, quizás más que cualquier otro personaje de esta aventura, una figura móvil, híbrida, producto de la cultura fronteriza. A lo mejor Corral manipuló lo que le dijo Cajeme según sus propios propósitos; pero la inteligencia de Cajeme no debe de subestimarse: es igualmente probable que el mismo Cajeme manejara su propia narración biográfica en sus entrevistas con Corral con la intención de orientar la interpretación que le hiciera éste. Cajeme, al fin y al cabo, tenía la ventaja de haber vivido en múltiples mundos.

El joven José María Leyva había sido educado en un distinguido hogar criollo, aunque fuera un mero criado allí. Su experiencia en el mundo criollo le facilitó más tarde su triunfo en las fuerzas armadas mexicanas con las que tomó parte en varias batallas contra los yaquis, ${ }^{16}$ obteniéndole el rango de capitán. D espués, llegó a disfrutar tanta confianza con las autoridades mexicanas que lo mandaron a ser "alcalde mayor" de los yaquis con el fin de que se mantuvieran pacíficos por la influencia de un administrador de su propia raza, quien les dominara mientras éste fuera siempre fiel al gobierno federal (Corral 154). El gobierno no contaba con la metamorfosis

${ }^{15}$ Esta biografía se publicó en 1887 en el periódico oficial de Sonora, L a C onstitución. Respecto a la elaboración y la influencia del texto de Corral, ver Z avala Castro 14-18.

${ }^{16}$ Una de estas batallas, una victoria para los mexicanos, acabó en la captura de cientos deyaquis, quienes fueron encarcelados en una especie de campo de concentración en la que casi cuatrocientos fueron masacrados (Zavala Castro 135). 
identitaria de Leyva, quien después de poco tiempo de alcalde ya no usaba su nombre "cristiano", prefiriendo llamarse "Cajeme" ("el que no bebe") y volviéndose el jefe insurgente más feroz y más sagaz de toda la historia de los conflictos yaquis con México. Era mexicano y era yaqui - y era, más que todo, un hombre fronterizo.

En 1849, a los doce años, el joven Leyva viajó con su padre a Alta California en la onda migratoria de la rebatiña de oro. Poco después, volvió a Sonora donde su padre le consiguió un trabajo en la casa de la distinguida familia Navarro en Guaymas. Según Corral, Leyva fue entonces inscrito por los Navarro en una escuela dirigida por el español Jorge Martinón. ${ }^{17}$ Allí estudiaba en 1854 cuando los franceses invadieron la ciudad, y como todo patriota, el joven Leyva se armó y participó entusiastamente en la defensa de Guaymas. D ada la falta de documentación sobre los individuos de las clases populares y de las razas oscuras de esa época, no hay manera de verificar la información que Cajeme le dio a Ramón Corral sobre este periodo de su vida. Lo que sí es interesante es que Yáñez no nombró ninguno de los jóvenes de esta escuela en sus informes y ningún participante o testigo blanco o mestizo se molestó en reconocer la colaboración de individuos de raza indígena en la batalla de Guaymas, a pesar del hecho de que una brigada yaqui del ejército mexicano jugó un papel importante en la derrota de Raousset (Wyllys 211). Por lo tanto, se han establecido dos historiografías discordantes: una basada en los informes oficiales de Yáñez donde Cajeme no participó en la batalla de G uaymas, y otra afirmada por la biografía de Cajeme por Corral en la que Cajeme sí participó como patriota mexicano en la batalla de G uaymas. No obstante el hecho de que como periodista con una predilección por la historia regional no cabe duda de que Pérez Peña conocía bien la biografía de Corral, el autor de H eroína eligió no recuperar el patriotismo del adolescente José María Leyva en su obra.

${ }^{17}$ Zavala Castro disputa esta versión al aseverar que ningún sirviente indio hubiera sido permitido asistir a una escuela (120). 
México - y Sonora en particular- no podía ser representado por un embustero rebelde fronterizo de piel morena, quien se transformó de patriota en revoltoso y humilló a las autoridades mexicanas por más de una década con una resistencia organizada que impedía la venta y explotación de las tierras fértiles de la valle del Río Yaqui. Muchos sonorenses estaban hartos ya en 1897 de las rebeliones de los yaquis, y pensaban que ya era hora de romperles la voluntad y vencerlos para siempre. En 1894, el mismo Pérez Peña había celebrado su inminente "pacificación" como "importantísima en el progreso de Sonora" ("Carta" iii). No es inaudito que éste eligiera no glorificar a su gran jefe que se burlaba por tantos años a los sonorenses letrados. A diferencia de Loreto de Avilés y Guadalupe Cubillas, Cajeme no era bueno para la imagen de México, ni debía figurar en la construcción de una identidad regional sonorense.

\section{Conclusiones}

La falta de evidencia textual ha dificultado el estudio de la cultura fronteriza del noroeste mexicano del siglo XIX. H eroína, la recién descubierta obra pionera de literatura sonorense, señala la necesidad de releer los pocos textos que hay de la época para reinterpretar la historia cultural del noroeste de México no como un conjunto de historias estatales de Sonora, de Baja California Norte y Sur, etc., fragmentos todas de una unidad nacional, sino como una historia fronteriza, la que sólo se entiende releyéndolos en diálogo con otros textos - de la ciudad de México, de Estados Unidos, etc.- que determinaban muchas veces los constructos identitarios que empezaban a forjar. $\mathrm{H}$ eroína incorpora estratégicamente algunas figuras marginalizadas de la historia fronteriza, en sus representaciones nacionales mexicanas o las elaboradas en el extranjero, recurriendo a la leyenda local para remoldear esta historia en una forma aceptable para los propósitos de la élite letrada de Sonora. Elige unas figuras mientras excluye metódicamente a otras, enfatizando no la pugna nacional (Méxicio versus Francia), sino el papel de lo local en tales conflictos. Una relectura de $\mathrm{H}$ eroína desde la frontera revela 
unos vestigios de la ideología racial que informaba al autor Aurelio Pérez Peña en sus empeños de representar a Sonora para que se viera bien tanto para los mexicanos del resto del país como para los observadores selectos (blancos, prósperos, modernos) del extranjero.

\section{Bibliografía}

Aldaco, Guadalupe Beatriz. "Literatura tradicional, cultural oficial en Sonora (1856-1870)." Lian Karp, et al. Cultura y literatura. Hermosillo: El Colegio de Sonora, 1989: 47-151.

Calvo Berber, Laureano. N ociones de historia del estado de Sonora. Hermosillo: Imp. Cruz Gálvez, 1941.

Corral, Ramón. "Biografía de José María Leyva Cajeme" [1887].

0 bras históricas. Hermosillo: Biblioteca Sonorense de Geografía e Historia, 1959: 147-92.

Dávila, Francisco T. Sonora histórico y descriptivo. Nogales, Arizona:

Tipografía de R. Bernal, 1894.

Garza, Ramiro de. "El caso de doña Loreto." Instituto Nacional de Antropología e Historia, Hermosillo, Sonora. "Artículos históricos sonorenses" Vol. 2, Ficha 8225 [sin fecha]: 375-79.

Glantz, Margo. Un folletín realizado: la aventura del conde $\mathrm{G}$ astón de Raousset-Boulbon [1973]. México: Fondo de Cultura Económica, 1988.

Iberri, Alfonso. E 1 viejo G uaymas. Hermosillo: Gobierno del Estado de Sonora, 1952.

Irwin, Robert McKee. The 0 ther Borderlands: C ultural Ions of M exioo's

N orthwestern Frontier, 1848-1910. Minneapolis: University of Minnesota Press, 2006.

López Encinas, Francisco. Sonora, frontera codiciada. Hermosillo: Sygma G ráfica, 1985.

López Yescas, Ernesto. "Ecos franceses en la historiografía de Sonora." Coord. Ignacio Almada Bay. Francia en Sonora. Hermosillo: Instituto Sonorense de Cultura, 1993: 119-27.

Moncada O., Carlos. D os siglos de periodismo en Sonora. Hermosillo, Ediciones EM, 2000. 
Pérez Peña, Aurelio. "Carta a guisa de prólogo." Francisco T. Dávila. Sonora histórico y descriptivo. Nogales, Arizona: Tipografía de R. Bernal, 1894: i-iv.

. H eroína: drama histório nacional. Guaymas: Tipografía de A. Ramírez, 1897.

Ramírez Cabañas, Joaquín. G astón de Raousset: conquistador de Sonora. México: Xóchitl, 1941.

Raousset-Boulbon, G. de. Une conversion. París: Librairie Nouvelle, 1855.

Rocha, Gilda. Sonora, un siglo de literatura: poesía, narrativa y teatro (1936-1992). México: Consejo Nacional para la Cultura y las Artes, 1993.

Ruibal Corella, Juan Antonio. H istoria general de Sonora Tomo III, Periodo México independiente: 1831-1883 [1885]. Hermosillo: Gobierno del Estado de Sonora/ Instituto Sonorense de Cultura, 1997.

Sobarzo, Horacio. Crónica de la aventura de Raousset-Boulbon en Sonora. México: Librería de Manuel Porrúa, 1954.

Tinker Salas, Miguel. In the Shadow of the E agles: Sonora and the Transformation of the Border during the Porfiriato. Berkeley: University of California Press, 1997.

Trueba, Alfonso. A ventura sin ventura (G astón de Raousset) [1954]. México: Jus, 1957.

Ulloa, Pedro N. Folleto conmemorativo de la memorable jornada del 13 de julio de 1854 [1907]. Hermosillo: Laura Romandía, Viuda de Ulloa, 1954.

Wyllys, Rufus Kay. The French in Sonora (1850-1854): The Story of French A dventurers from California into M ex ico. Berkeley: University of California Press, 1932.

Yáñez, José María. "Informe del gobernador y comandante general de Sonora, donde comunica los resultados de la acción de G uerra, en G uaymas, que culminó con la derrota de las fuerzas invasoras, en julio de 1854, encabezadas por G astón Raousset de Boulbon" [1854]. Comp. Mario Cuevas Arámburo. Sonora: tex tos de su historia Vol. 2. Hermosillo/ México: G obierno del Estado de Sonora/ Instituto de Investigaciones Dr. José María Luis Mora, 1989: 119-30. 
Zavala Castro, Palemón. E l indio Cajeme y su nación del Río Yaqui. A capulco: Gobierno del Estado de Sonora/ Secretaría de Fomento Educativo y Cultura, 1985.

\section{Peniódicos}

El Imparcial, Guaymas y Hermosillo.

The N acional Police G azette, Nueva York.

The Star, Los Ángeles.

El Universal, México, D. F. 